REVIEW ARTICLE

\title{
Reasons of Absenteeism among Undergraduate Medical Students: A Review
}

\author{
*T Sharmin ${ }^{1}$, E Azim² ${ }^{2}$ S Choudhury ${ }^{3}$, S Kamrun $^{3}$ \\ ${ }^{* 1}$ Dr. Tanima Sharmin, Assistant Professor, Department of Community Medicine, Green Life Medical College, Dhaka \\ ${ }^{2}$ Dr. Ehsamul Azim, Associate Professor, Department of Community Medicine, Green Life Medical College, Dhaka \\ ${ }^{3}$ Dr. Shamima Choudhury, Lecturer, Department of Community Medicine, Green Life Medical College, Dhaka \\ ${ }^{4}$ Dr. Sayma Kamrun, Lecturer, Department of Community Medicine, Green Life Medical College, Dhaka \\ * Corresponding Author
}

Date of submission: 02. 09. 2016 Date of acceptance: 05. 12. 2016

\begin{abstract}
Absenteeism refers to the frequent absence from classes without any good reason. In spite of compulsory attendance rule, individual students, parents, institute and society suffer when students do not attend classes in medical college on regular basis. Student absenteeism is a concern in higher education especially medical education. Student's absenteeism results in inadequate learning and poor academic performance. Despite the strict rules, absenteeism is an on-going problem in many universities and a phenomenon that is also on the rise in universities worldwide. There is extensive literature on the link between absenteeism and lack of subject matter interest, poor teaching strategies, unfavorable learning environment,excessive socialization among students, part-time jobs, ill health, sleeplessness and poor relations with lecturers. In addition, accessibility of lecture content in the form of online slides, videos and audios has their own contribution to absenteeism. Early detection and prevention might prevent unwanted consequences of absenteeism on medical students' academic performance.Medical colleges should pay more attention and take immediate measures on those who starting to absent from classes because they might need support from them.
\end{abstract}

Key Wards: Absenteeism, medical students

\section{Introduction}

One of the most vital considerations among students in higher educational level is academic performance though there are some differences in performance among the students. ${ }^{1}$ The goal of undergraduate medical education is to produce a physician with adequate knowledge of health and diseases, reasonable medical skills and a healthy attitude towards patients and their families. ${ }^{2}$ Student attendance is thought to be an important factor in the academic performance of medical students on the basis that clinical contact and teaching are necessary to develop competence. Lectures remain one of the important modes of teaching in many medical colleges despite adaptation of new curriculum. It is easy to deliver knowledge through lecture to a large number of students and logistically saving resources. Low attendance in lectures is not a

AKMMC J 2017; 8(1) : 60-66 new problem. ${ }^{3}$ Number of causative factors has been suggested. ${ }^{4}$ With the revolution in the electronic equipment ${ }^{5}$ there are varieties of computer based softwares to assist in making the lectures more presentable, interesting and interactive, thus making the traditional teaching effective. ${ }^{6}$ Despite this development low attendance at lectures is still an issue. Absenteeism at higher education level affects the learning process of the students as well as the final result at the end of academic session. ${ }^{7,8}$

Several studies identify internal and external factors associated with academic performance. Class absenteeism is one of the factor that has negative effect on the mastery of the academic curriculum. One of the most useful work done by Kelland et $\mathrm{al}^{8}$ reported that a decrease in the examination result 
score with increase in the number of absencesin classes during human physiology course. In the study by Fielet $\mathrm{al}^{9}$ it has been demonstrated that significant learning occur during the lectures but. In the study by Riggs et $\mathrm{al}^{10}$ a negative correlation is shown between percent absences and examination scores, suggesting the value of monitoring attendance and identifying students at risk for poor performance. Sabujet $\mathrm{al}^{11}$ in Bangladesh found that absenteeism affects academic performance among undergraduatepaediatric medicine students. ${ }^{12}$

The lower attendance rate among students who previously failed an end-of-year examination suggests that previous poor academic performance may be associated with subsequent poor attendance. The medical students were more likely to miss classes than health science students (Nursing, Health Officer, Midwifery, Laboratory Technology, Optometry, and Environmental Health) despite the medical curriculum requirement of $100 \%$ class attendance unless the student has legitimate reasons for missing class. This could explain why academic delays and dismissals from the program are commonly observed among medical students, particularly during the final years in medical colleges. If this behavior continues after medical education, it will reflect on their work life and therefore, may affect the quality of health service in the future. ${ }^{11,13,14}$

In our country medical education are still following the traditional lecture format of teaching. Lectures and classroom discussion represent the primary means of teaching for undergraduate medical students. Students who miss a lot of classes perform poorly on exams because they were not present when the topics were covered, alternatively students with high levels of absenteeism less committed to academics in general. ${ }^{15}$ Lecture and tutorials provide a platform where students interact with the teachers, observe them and distinguish them as role models. Low attendance hence may affect this process and hinder their professional growth. ${ }^{16}$ On the other hand the role of teachers in improving student's attendance in lectures can not be denied. Teachers with good teaching skills deliver lectures which are organized and structured; have good communication skills which attract students and shows higher attendance rates. ${ }^{17}$ Despite the strict rules, absenteeism is an on-going problem in many universities and a phenomenon that is also on the rise in universities worldwide. ${ }^{18-20}$

There is extensive literature on the link between absenteeism and lack of subject matter interest, poor teaching strategies, unfavorable learning environment, excessive socialization among students, part-time jobs, ill health, sleeplessness, and poor relations with lecturers. ${ }^{17,18,20-22}$ In addition, accessibility of lecture content in the form of online slides, videos, audios have their own contribution to absenteeism. ${ }^{23-27}$

Absenteeism will only allow students not to obtain appropriate information and contact with relevant material (lectures, practical session, clinical skills, etc) that is required for effective learning to occur. In addition, regular attendance in learning activities corresponds to a distributed practice system (i.e. the students allocate learning effort throughout a course over multiple and short duration of learning sessions) that is effective to increase the retention of knowledge. Study conducted in Saudi Arabia by BinSaeedet $\mathrm{al}^{28}$ showed that student absenteeism may contribute to low achievement or vice versa. Under-achievement assumes critical importance for medical care providers who are involved in decision making in life and death situations.

As educators, we want our students to attend classes. We enjoy teaching and interacting with students and work hard to make our classes worthy of the student's time and energy. We know who our best students are because they attend class regularly, but we often have a hard time putting a face to the names of the students that fail. On the basis on this anecdotal evidence, we assume that students who attend class regularly benefit from the lectures, tutorials and learning activities designed to facilitate their acquisition of knowledge. Conversely, we assume that excessive absences from class results in poor academic performance. These assumptions, however, are not based on empirical evidence.This review will highlight the reasons of absenteeism among undergraduate medical students.

\section{Factors related to medical students}

The major reasons for missing lectures were preparing for another examination, inconvenient class schedule, lack of interest in the subject matter, 
dislike of teaching style and the ease of understanding the subject matter without guidance. ${ }^{29}$ A high number of students remain absent in the pre examination period, which could be explained by their allotting of this time for more intensive study before the exams. ${ }^{28,30}$ Absence in the pre-exams period and at the end of the year is may be due to lack of preparedness, so the students prefer to spend time on study rather than attending lectures. ${ }^{31}$ Many college students have extremely poor time management skills. The most obvious sign of poor time management is spending time in extracurricular activities like attending parties, watching TV, browsing internet, etc instead of studying which may cause fatigue making the student unable to concentrate in classes. Many students think that they can easily clear their exams so they spend time in other activities. This attitude is found hazardous for a medical student in an Indian study.30Unlike school teaching, medical education move quickly through large portion of study material. Classes that are missed entirely often cannot be made up. Some students wait till exam dates are announced and quickly rush through the books and guides thereafter. The student then tries to cover many material in few hours. ${ }^{32}$

Another common reason for absenteeism is sickness. Unexpected life situation can occur like illness of student or illness of a family member or a family problem and then the student is forced to miss classes. ${ }^{33}$ Class absenteeism due to menstrual disorders is common among female medical students. ${ }^{34}$ Getting to bed late in the night and feeling tired in class are other common reasons for absenteeism. ${ }^{33}$

Even though medical students opt for the course by choice, they may find the course work more rigorous and demanding than anticipated. Absenteeism can be one convenient way to escape the curriculum. ${ }^{35}$ Participants lack of interest in the subject might be the reason for absenteeism. ${ }^{36}$ Lack of interest in the subject matter could be attributed to two reasons: 1) the likelihood that the majority of health science students are assigned to the field probably against their choice; 2) even though medical students elect to be on the medical track, they may find the course work more rigorous and demanding. ${ }^{29,30}$
Hafeez et $\mathrm{al}^{37}$ in Pakistan found two top most reasons why students don't attend lectures were; the timings of the lectures were not adjusted according to their schedule and that they preferred self/group study over lectures. According to Desalegnet $\mathrm{al}^{29}$ the absence in the morning lectures is higher than absence in the afternoon lectures that can be due to delay going to bed. So early-morning classes is another cause of absenteeism. There is better attendance at lectures scheduled in the middle of the day when students are already likely to be on campus. ${ }^{38}$ Transport problem also is a reason for absenteeism. ${ }^{39}$

Student absenteeism was significantly associated with marital status and part-time job. The married students and those who have part time jobs are more susceptible to absence due to non-academic workloads. ${ }^{31}$ Social drug use was very strongly associated with being absent from lectures. Studies have shown that substance abuse ${ }^{40}$ and alcohol consumption $^{41}$ are risk factors for prevalent and unexcused absence from lectures. Additionally, students with low motivation are more likely to engage in social drug use. ${ }^{42}$ Society related causes such as low societal value for educationis also identified as the reasons for absenteeism in classes. ${ }^{43}$ Poor family relation sometimes play role in absenteeism. ${ }^{39}$ Psychological factor like peer pressure may contribute to it. ${ }^{33}$

\section{Factors related to teaching stuff}

Lectures involved teaching a lot of students in a single large class room and test the ability of a teacher how efficiently he conveys the knowledge and keeps the students attentive. The qualities of teachers, their practices and the relationship they have with their students appears to play a role in non-attendance to lectures. ${ }^{22}$ More specifically, disorganized lecturers who do not engage with students and are perceived as boring, will see lower numbers of attendance. ${ }^{44}$ Teachers should take efforts to make subject more interesting useful and relevant. Teachers need to adopt creative teaching methodology techniques. There should be a proper plan to encourage student's feedback, so that teaching can become more meaningful. Studentsmay feel that teacher is not able to motivate them sufficiently. Not only student behavior, but also teacher's attitude and teaching methodologies appear 
Reasons of Absenteeism Among Undergraduate Medical Students

to play a role in student absenteeism from classes. Teachers must make sure that classrooms are dynamic. ${ }^{35}$ Poor teaching skills of lecturers leading to boring lectures. ${ }^{39,45}$ Dislike for teaching style and the ease of understanding the subject without guidance is also a contributing factor for absenteeism. ${ }^{29}$ Lack of clarity about the topic among teachers while teaching is a contributing reason for absenteeism. 30

\section{Factors related to teaching material/strategy}

The interaction in lecture is part of the professional socialization process in which students observe faculty members and recognize them as role models. ${ }^{46}$ The lecture-based teachings are capable to enhance skills related to cognitive, affective and psychomotor. ${ }^{47}$ Historically, reports suggested that attendance is better at lectures compared to small group teaching. ${ }^{48}$ However, modern publications have suggested that students prefer self-study or smaller teaching sessions, and quote this as a reason for non-attendance at larger group sessions. ${ }^{49}$ In a recent publication, $70 \%$ of students preferred small group teaching to larger lectures but still recognised that lectures form a fundamental part of education. ${ }^{37}$ Omrod et al ${ }^{50}$ reports that some students seem to learn better when information is presented through words (verbal learners), whereas others seem to learn better when it is presented in the form of pictures (visual learners). Clearly in a class where only one instructional method is employed, there is a strong possibility that a number of students will find the learning environment less optimal and this could affect their academic performance.Attendance is poor when lecture slides are available to students prior to lectures, compared to when unavailable. This suggests that students believe they can achieve the same level of knowledge from the resources provided regardless of attendance. ${ }^{51}$ There are numerous positives to accessing online resources. Students often struggle to make organised, thorough lecture notes for revision. Having a template in the form of pre-released slides could potentially rectify this problem and improve revision techniques. ${ }^{52}$ Accessibility of lecture content in the form of online slides, videos and audios have their own contribution to absenteeism. ${ }^{22}$ Another study reported that continuous assessment marks were lower in pharmacology students, where students followed online lecture recording instead of classroom lecture. Student must be physically present and mentally receptive for learning to occur. ${ }^{46}$ Students who choose to skip lecture-based teachings and rely solely on other modes of learning with the class subject are less likely to retain relevant knowledge related to the subject as compared to those who attend the class; subsequently those who absent perform poorly on the examinations. ${ }^{11}$

One study showed that $80 \%$ of medical students chose to attend specific lectures dependent on the lecture topic itself, while another found that $69 \%$ of students cite interest in the topic as a key reason for attendance. ${ }^{53,54}$ Even though the argument on the comparative benefits of different instructional designs (e.g., small group discussion, problem based learning, lectures, tutorials, practical demonstrations, and bed side clinical teaching) continues ${ }^{11}$,skipping class is expected to be unbeneficial for learning even the best and most sophisticated instructional designs used by educators. Even lecture-based teaching seems to provide substantial benefits for learning to take place despite its didactic in nature ${ }^{55}$, poor feedback, and inability to engage in authentic practice. ${ }^{11}$ Lengthy classes are another contributing reason for absenteeism. ${ }^{30}$ Scheduling one lecture in a day has a negative effect on attendance. Multiple lectures in one day result in better attendance. ${ }^{51}$

\section{Factors related to medical college}

The comforts of home are desirable from a lonely and discouraged student at medical colleges. A student remain absent because the class environment is not conducive enough for learning.Poorly ventilated lecture hall, overcrowding in the classrooms and uncomfortable sitting arrangement in class are important factors for not attending class. ${ }^{33}$ Poor infrastructure was also found to be one of the reasons for absenteeism. ${ }^{30}$

\section{Bangladesh situation}

Educational institutions around the world have been increasingly confronted with the challenge of making their curricula relevant to the needs of the time. Medical education in Bangladesh has also experienced many changes and challenges. ${ }^{56}$ Last decade can be considered as the "golden age" of 
medical education in Bangladesh. One of the important developments in recent years in medical education in Bangladesh is the establishment of a large number of medical colleges both in govt. and private sector. Currently, there are more than 100 medical colleges in Bangladesh. ${ }^{57}$

Medical education system in Bangladesh inherited the typical features of colonial education, which is very much on the traditional pattern: lecture-based, teacher-centered, discipline-based, examinationdriven, and hospital-oriented. ${ }^{58}$ Reorientation of medical education is needed along with policy settings to attract students. Mia et $\mathrm{al}^{59}$ conducted a study among three government and four nongovernment medical colleges in Bangladesh and found that the most important reasons for dropouts and defaulters were lacking of personal interest and less capability for understanding the medical subjects, non-friendly and non-cooperative attitude of teachers and content overloaded curriculum; personal illness and illness of family members and poor institutional set up. This review also found the similar reasons why students remain absent in classes. Strict regularity, sincerity and attention should be paid to all types of classes including lectures, clinical, tutorial and practical can change the situation. A coordinated class, tutorials and examination system should be developed in each medical college, so that all students can prepare themselves for examination properly. Sultana et al60observed that medical students experience a higher level of personal distress during their undergraduate course in Bangladeshi.High levels of stress may have a negative effect on mastery of the academic curriculum. Teachers and examiners at all levels should be friendly and cooperative, and should pay special attention to the students to overcome their weaknesses.

\section{Conclusion}

Creating awareness among medical students about the effect of absenteeism on their academic performances may prevent them from skipping classes. Medical colleges also should pay more attention and take immediate measures on those who starting to absent from classes because they might need support from them. Early detection and prevention might prevent unwanted consequences of absenteeism on medical student's academic performance. Application of strict attendance policy may influence student attendance and medical colleges should reinforce the attendance policy as an effort to improve their student's academic performance.

\section{Reference}

1. Trice AD, Holland SA, Gange PE. Voluntary class absences and other behaviors in college students, An exploratory analysis. Psychology Reports 2000; 87: 17982.

2. Synder BR. The hidden curriculum. New York: Knopf; 1971.

3. Kottasz R. Reasons for student non-attendance at lectures and tutorials: an analysis. Invest Uni Teach Learn 2005; 2: 521 .

4. Chodorow S. Educators must take electronic revolution seriously. Acad Med 1996; 71: 221-6.

5. Waugh RA, Mayer JW, Ewy GA, Felner JM, Issenberg BS, Gessner IH, et al. Multimedia computer assisted technology. Arch Intern Med 1995; 155: 197-203.

6. Friedman P, Rodriguez F, McComb J. Why students do and do not attend classes: myths and realities. Coll Teach 2001; 49: 124-33.

7. Khan HU, Khattak AM, Mahsud IU, Munir A, Ali S, Khan $\mathrm{MH}$, et al. Impact of class attendance upon examination results of students in basic medical sciences. J Ayub Med Coll Abbottabad 2003; 15: 56-8.

8. Hammen CS, Kalland JI. Attendant and grade in human physiology course. Advan inn physiolEdu. 1994; 267: s105.

9. Fiel NJ. The Lecture: increasing student learning. Med Educ 1996; 51: 496-99.

10. Riggs JW, Blanco JD. Is there a relation between student lecture attendance and clinical science subject examination score? Obstet Gynecol 1994; 84: 311-13.

11. Crede M, Roch SG, Kieszczynka UM: Class Attendance in College A Meta-Analytic Review of the Relationship of Class Attendance with Grades and Student Characteristics. Review of Educational Research 2010, 80(2): 272-295.

12. Sabuj MKH, Shaha C. Class absenteeism in Pediatrics and its impact on performance: An analytical study on undergraduate students of a Medical College Hospital in Dhaka. Bangladesh Journal of Child Health 2015; 39: 69-72. 
13. Hidayat L, Vansal S, Kim E, Sullivan M, Salbu R. Pharmacy student absenteeism and academic performance. Am J Pharm Educ. 2012; 76(1): 8.

14. Obeidat S, Bashir A, Abu JW. The importance of class attendance and cumulative gpa for academic success in industrial engineering classes. Int J Soc Hum Sci. 2012; 6: $139-42$.

15. Hammer DP, Berger BA, Beardsley RS, Easton MR. Student professionalism. Am J Pharm Educ 2003; 67: 1-29.

16. Massingham P, Herrington T. Does attendance matter? An examination of students' attitudes, participation, performance andattendance? J Uni Teach Learn Pract 2006; 3: 83103.

17. Wadesango N, Machingambi S: Causes and structural effects of student absenteeism: a case study of three South African Universities. J Soc Sci. 2011, 26: 89-97.

18. Kottasz R: Reasons for student non-attendance at lectures and tutorials: an analysis. InvestigUniv Teach Learn. 2005, 2: 5-16.

19. Gump SE: Guess who's (not) coming to class: student attitudes as indicators of attendance. Educ Stud. 2006, 32: 39-46.

20. Obeng-Denteh W, Yeboah EA, Sam C, Monkah JE: The impact of student and teacher a4bsenteeism on student performance at the junior high school: the case of the Kumasimetro school district. Cont J Educ Res. 2011, 4: 7-17.

21. Moore R: The importance of admissions scores and attendance to first-year performance. J First-Year Exp Students Transit. 2006, 18 (1): 105-125.

22. Bati AH, Mandiracioglu A, Orgun F, Govsa F: Why do students miss lectures? A study of lecture attendance amongst students of health science. Nurse Educ Today. 2013, 33 (6): 596-601. 10.1016/j. nedt.2012.07.010.

23. Massingham P, Herrington T: Does attendance matter? An examination of student attitudes, participation, performance and attendance. J Univ Teach Learn Prac. 2006, 3 (2): 82-103.

24. Cook DA: The research we still are not doing: an agenda of the study of computer-based learning. Acad Med. 2005, 80 (6): 541-548.

25. Ruiz JG, Mintzer MJ, Lepizig RM: The impact of Elearning in medical education. Acad Med. 2006, 81 (3): 207-2012.

26. Davis EA, Hodqson Y, Macaulay JO: Engagement of students with lectures in biochemistry and pharmacology. BiochemMol Bio Educ. 2012, 40 (5): 300-309.

27. Fernandes L, Maley M, Cruickshank C: The impact of online lecture recording on learning outcomes in pharmacology. J IntAssoc Med Sci Educ. 2008, 18: 62-70.
28. BinSaeed AA, Otaibi MS, Ziyadi HG, Babsail AA, Shaik SA (2009). Association between student absenteeism at a medical college and their Academic Grades. Med. Sci. Educ. (JIAMS), 19(4):155-9.

29. Desalegn AA, Berhan A, Berhan Y. Absenteeism among medical and health science undergraduate students at Hawassa University, Ethiopia. BMC Med Educ. 2014; 14: 81.

30. Rao BT, Valleswary K, Nayak MSDP, Rao NL. Reasons for Absenteeism among the Undergraduate Medical Students Attending for Theory Classes in Rajiv Gandhi Institute of Medical Sciences (RIMS) Ongole, Prakasam District of Andhra Pradesh: A Self Review. IOSR Journal of Research \& Method in Education (IOSR-JRME). 2016; 6: 11-19.

31. Alghamdi A, Yamani A, Khalil A, Albarkati B, Alrehili $\mathrm{O}$, Salih M. Prevalence, Causes and Impacts of Absenteeism among Medical Students at UQU. Education 2016, 6(1): 9-12.

32. Park k, Kerr P. Determinant of Academic performance: A Multinomial Logit Approach. J. Econ. Educ. Spring 1990; 21: 101-11.

33. Dashputra A, MeenalKulkarni M, Chari S, Date A. Medical students' absenteeism in class: reasons and remedies. Journal of Educational Research and Studies January 2015; 3(1): 24-29.

34. Shete J S, Warbhe P, Padmini D. Class absenteeism among female medical students: A study reflecting its association with common menstrual disorder. International Journal of Recent Scientific Research Research.2015; 6:5307-09.

35. Ramodike SP (2007). Students Absenteeism in the FET Sector, Particularly NCV. Student Support Services. South African College Pricipals Organisation (SACPO) (Internet). In The Everyday Bible, Thomas-Nelson publisher, Available from https: /www. Pdfbooky.com/ncv (accessed on05/ 12/2013.

36. Moorea S, Armstronga C, Pearsona J. Lecture absenteeism among students in higher education: a valuable route to understanding student motivation. J. High. Educ. Policy Manag. 2008; 30(1): 15-24.

37. Hafeez K, Khan MLZ, Jawaid M, Haroon S. Low attendance in lectures at medical colleges of Karachi - A cross sectional survey. J Postgrad Med Inst 2014; 28(2): $161-64$

38. Kelly GE. Lecture attendance rates at university and related factors. J Furth High Educ. 2012; 36(1):17-40.

39. Tripura K, Das R, Saha N. Attitude of medical students towards the reasons of absenteeism in a medical college of Tripura .IOSR Journal of Dental and Medical Sciences (IOSR-JDMS).2015; 14: 110-12. 
40. Kearney AK. School absenteeism and school refusal behavior in youth: a contemporary review. ClinPsychol Rev. 2008; 28(3): 451-71.

41. Wyatt G. Skipping class: an analysis of absenteeism among first-year college students. Teach Sociol. 1992; 20(3): 201-07.

42. Zimmerman MA, Schmeelk-Cone KH. A longitudinal analysis of adolescent substance use and school motivation among African American youth. J Res Adolesc. 2003; 13: 185-210.

43. Fayombo GA, Ogunkola BJ, Olaleye YL. Cross Institutional Study of the Causes of Absenteeism among University Students in Barbados and Nigeria. Journal of Educational and Developmental Psychology May 2012; 2(1): 122-36.

44. PerskyAM,Kirwin JL, Marasco CJ, May DB, Skomo ML, Kennedy KB. Classroom attendance: Factors and perceptions of students and faculty in US schools of pharmacy. Curr Pharm Teach Learn. 2014; 6(1): 1-9.

45. Fayombo GA, Ogunkola BJ, Olaleye YL. Cross Institutional Study of the Causes of Absenteeism among University Students in Barbados and Nigeria. Journal of Educational and Developmental Psychology May 2012; 2(1): $122-36$

46. Fjortoft N. Student?s motivations for class attendance. Am J Pharm Educ. 2005; 69(1) Article 15.

47. Arthur Jr W, Bennett Jr W, Edens PS, Bell ST. Effectiveness of training in organizations: a metaanalysis of design and evaluation features. Journal of Applied Psychology. 2003, 88(2): 234-45.

48. Baderin M. Towards improving students' attendance and quality of undergraduate tutorials: A case study on law. Teach High Educ. 2005; 10:99-116.

49. Westrick SC, Helms KL, McDonough SK, Breland ML. Factors influencing pharmacy students' attendance decisions in large lectures. Am J Pharm Educ. 2009; 73(5).

50. Omrod, J. E. Educational psychology: developing learners. Sixth Edition. Upper Saddle River, New Jersey: Pearson Education; 2008.
51. Edward J. Nevins, Parisa L. Moori, Leanne Alexander, Bethany Richards, Victoria Bleasdale, Ajay K. Sharma. Could Attendance at Medical School be improved? A Prospective Study of Medical Education at The University of Liverpool: Study of Attendance at a UK Medical School. OmeeMedEdPublish. 2016.DOI: http://dx.doi.org/10.15694/mep.2016.000078.

52. Chen J, Lin T-F. Class Attendance and Exam Performance: A Randomized Experiment. J Econ Educ. 2008; 39(3): 213-27.

53. Westrick SC, Helms KL, McDonough SK, Breland ML. Factors influencing pharmacy students' attendance decisions in large lectures. Am J Pharm Educ. 2009; 73(5).

54. Billings-Gagliardi S, Mazor KM. Student decisions about lecture attendance: do electronic course materials matter? Acad Med. 2007; 82(10): S73-S76.

55. Bligh D: Whatas the use of lectures?, 5th edn. San Francisco: Jossey-Bass; 1998.

56. Amin Z, Merrylees N, Hanif A, Talukder MH. Medical education in Bangladesh. Med Teach. 2008; 30(3): 243-247.

57. Majumder MAA. Medical education in Bangladesh: past successes, future challenges. Bangladesh Med J. 2003; 32: $37-39$

58. Miah MA, Khan MAW, Talukder MHK, Begum F, Nargis T, Ferdous Khan TF, et al. Reasons of Dropouts and Defaulters of Medical Students in Bangladesh. Bangladesh Journal of Medical Education. 2011; 2(2) 2011: 1-6.

59. Bangladesh Health Bulletin 2015. Available at: http://www.dghs.gov.bd.

60. Sultana N. Stress and Depression among undergraduate Medical Students of Bangladesh. Bangladesh Journal of Medical Education. 2011; 2(1): 6-9. 